\title{
Vertebral Artery Dissection Occurring with Dizziness and Vomiting
}

\author{
Serhat Karaman', Murat Uysal² \\ 'Department of Emergency Medicine, Gaziosmanpaşa University School of Medicine, Tokat, Turkey \\ 2Department of Anatomy, Gaziosmanpaşa University School of Medicine, Tokat, Turkey
}

Cite this article as: Karaman S, Uysal M. Vertebral Artery Dissection Occurring with Dizziness and Vomiting. J Emerg Med Case Rep 2018; 9: 63-4.

\begin{abstract}
Introduction: Arterial dissections are becoming increasingly common among the causes of cerebrovascular diseases in the young. The dissections are less common in the vertebrobasilar system than in the carotid artery system. Here we report a case of vertebral artery dissection diagnosed after sudden neck movements with dizziness and vomiting.

Case Report: A 32-year-old male patient with no significant past medical history presented to our emergency clinic with dizziness, nausea, and vomiting. Cervical magnetic resonance imaging (MRI) angiography revealed an aspect coherent with dissection in the right extracranial vertebral artery.

Conclusion: Although rare, vertebral artery dissection should always be included in the differential diagnosis of dizziness.

Keywords: Vertebral artery dissection, dizziness, neck movement

Received: 07.11.2017 Accepted: 19.12.2017
\end{abstract}

\section{Introduction}

Vertebral artery dissection occurs with the rending of subintimal or subadventitial tissue layers in the vessel wall and the subsequent entry of blood in the tissue range; as a result, blood flow in the vessel lumen is disrupted (1, 2). At 2\% of ischemic stroke, vertebral artery dissection (VAD) has been observed. If the patient who has dissection does not have a known trauma story, it is called spontaneous artery dissection. It is usually seen in parts of the extracranial arteries inside the cerebrum and is rarely seen in vertebral artery $(2,3)$. VAD is a common cause of stroke in the young. The most common symptoms are dizziness and drowsiness (4). This article reports the case of a 32-years-old man with VAD who presented dizziness and vomiting after sudden neck movements.

\section{Case Report}

A 32-year-old male patient with no significant past medical history presented to our emergency clinic with dizziness, nausea, and vomiting. On the physical examination of the patient, there was no neurological deficit. There were no pathological findings in electrocardiography ECG, and his vitals were stable. He reported that his symptoms began after sudden neck movements, which did not improve with symptomatic treatment. Cranial, spinal radiography and computed tomography (CT) images taken to describe the clinical condition of the patient did not show any sign of bleeding or ischemia Brain diffusion-weighted magnetic resonance imaging (MRI) revealed diffusion restriction at the right cerebellar region, which is coherent with ischemia (Figure 1). Cervical MRI angiography (MRA) revealed an aspect coherent with dissection in the right extracranial vertebral artery (Figure 2). The patient was hospitalized and antithrombotic drug therapy started. Informed consent was obtained from the patient for the publication of this case. 


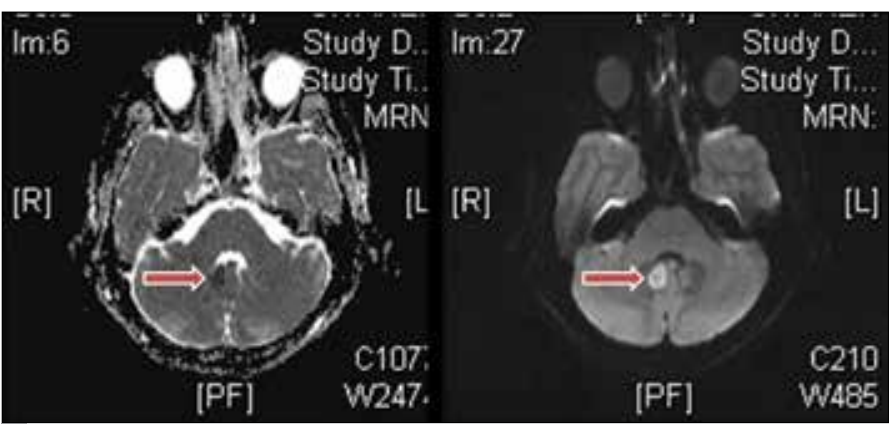

FIGURE 1. The brain diffusion-weighted MRI showing the right cerebellar ischemia (arrows).

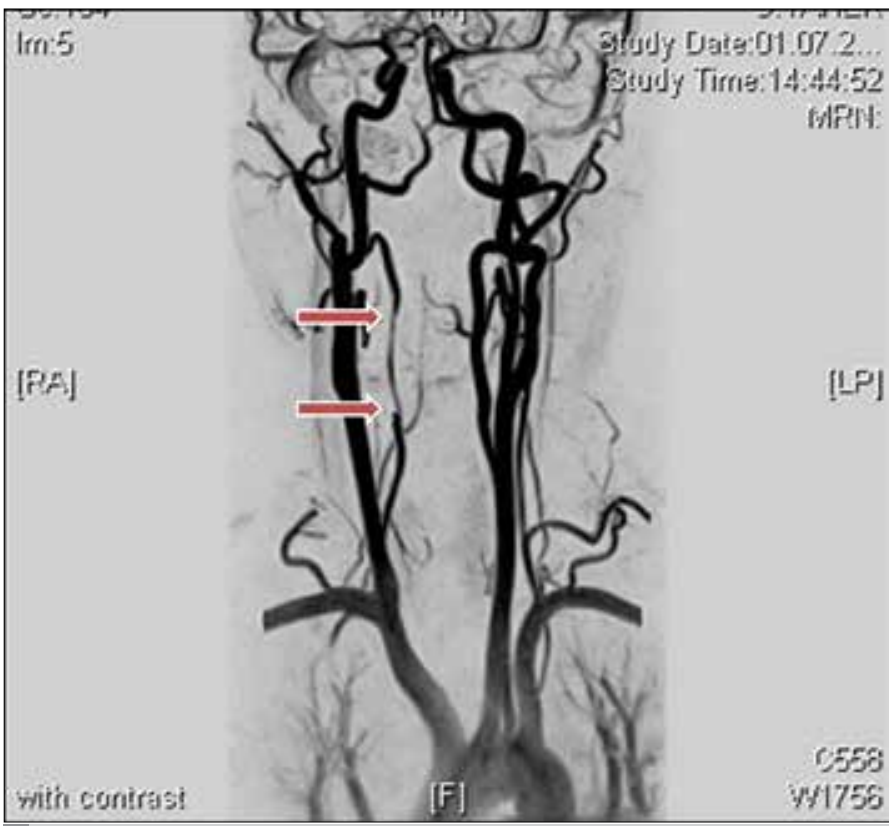

FIGURE 2. The dissection in the right extracranial vertebral artery as seen in the cervical MRI angiography (arrows).

\section{Discussion}

Vertebral artery dissection (VAD) may follow manipulation of the neck or a trauma but it can also occur spontaneously (5). In this case report, the patient reported that his symptoms began after a nonsevere neck movement. The most common symptom is dizziness, which is usually accompanied by diplopia, nystagmus, hemiparesis, gait ataxia, and numbness (6). However, in our case, there were no neurological findings accompanying dizziness. Up to $92 \%$ of patients are referred to emergency departments with the complaint of head and/or neck pain. The sudden onset of new headache is present in approximately $25 \%$ of cases (7). Unlike this clinical presentation, our patient did not complain of headache. The diagnosis of VAD is usually established by MRA or CT angiography (CTA) (8). Yaghi et al. (9) showed that traumatic and spontaneous dissections were more likely to be diagnosed by CTA and MRA, respectively. In accordance with this study, acute VAD was diagnosed with MRA in our case. Currently, there is no consensus on proper management for VADs. Usually, patients are initially treated with heparin, followed by warfarin or antiplatelet drugs alone (10). In this case, antiplatelet therapy was started in the emergency department.

In summary, although rare, VAD should always be included in the differential diagnosis of dizziness. Furthermore, it should also be kept in mind that neurological findings and head and/or neck pain may not always accompany the clinical picture of VAD.

Informed Consent: Written informed consent was obtained from patient who participated in this study.

Peer-review: Externally peer-reviewed.

Author Contributions: Concept - S.K.; Design - S.K.; Supervision - S.K.; Resources - M.U.; Materials - M.U.; Data Collection and/or Processing - M.U.; Analysis and/or Interpretation - S.K.; Literature Search - S.K.; Writing Manuscript - S.K.; Critical Review - M.U.

Conflict of Interest: The authors have no conflict of interest.

Financial Disclosure: The authors declared that this study has received no financial support.

\section{References}

1. Akay DKM, İzci DY, Urel DF, Baysefer DA, Timurkaynak DE. Traumatic dissection of bilateral vertebral arteries. Ulus Travma Acil Cerrahi Derg 2003; 9: 72-5

2. Ozemir ZA, Tolun R. Serviko-sefalik arter yeldisseksiyonlarda nörogörüntüleme ve endovasküler tedavi (karotis, vertebral, intrakraniyal). Turkiye Klinikleri J Neurol-Special Topics 2011; 4: 101.

3. Sarıbaş O. Servikosefalik arterlerin spontandiseksiyonu. Türk Beyin Damar Hast Derg 2008;14: 5-7.

4. Gottesman RF, Sharma P, Robinson KA, Arnan M, Tsui M, Ladha K, et al. Clinical characteristics of symptomatic vertebral artery dissection: a systematic review. The Neurologist 2012; 18: 245-54. [CrossRef]

5. Mann T, Refshauge KM. Causes of complications from cervical spine manipulation. Aust J Physiother 2001; 47: 255-66. [CrossRef]

6. Savitz SI, Caplan LR. Vertebrobasilar disease. N Engl J Med 2005; 352: 2618-26. [CrossRef]

7. Saeed AB, Shuaib A, Al-Sulaiti G, Emery D. Vertebral artery dissection: warning symptoms, clinical features and prognosis in 26 patients. Can $J$ Neurol Sci 2000; 27: 292-6. [CrossRef]

8. Jones J, Jones $C$, Nugent K. Vertebral artery dissection after a chiropractor neck manipulation. Proc (Bayl Univ Med Cent) 2015; 28: 88-90. [CrossRef]

9. Yaghi S, Maalouf N, Keyrouz SG. Cervical artery dissection: risk factors, treatment, and outcome; a 5-year experience from a tertiary care center. Int J Neurosci 2012; 122: 40-4. [CrossRef]

10. Kai Y, Nishi T, Watanabe M, Morioka M, Hirano T, Yano S, et al. Strategy for treating unruptured vertebral artery dissecting aneurysms. Neurosurgery 2011;69: 1085-91. [CrossRef] 